\title{
Decrease in Regulatory T-cells and Increase in T Helper 17 Cells in Women With Recurrent Spontaneous Abortion
}

\section{Mina Badiee}

Ahvaz Jundishapur University of Medical Sciences

Mehri Ghafourian ( $\sim$ ghafourian-m@ajums.ac.ir)

Ahvaz Jundishapur University of Medical Sciences: Ahvaz Jondishapour University of Medical Sciences

Ata A. Ghadiri

Ahvaz Jundishapur University of Medical Sciences

Abdolah Mousavi Salehi

Ahvaz Jundishapur University of Medical Sciences

Roshan Nikbakhat

Ahvaz Jundishapur University of Medical Sciences

\section{Rahim Chinipardaz}

Shahid Chamran University

\section{Research Article}

Keywords: Recurrent Spontaneous Abortion, FoxP3, RORyt, T-cells, Cytokines

Posted Date: December 9th, 2021

DOI: https://doi.org/10.21203/rs.3.rs-1098129/v1

License: (1) This work is licensed under a Creative Commons Attribution 4.0 International License.

Read Full License 


\section{Abstract}

\section{Background}

Appearance of improper immune responses against the fetus and/or inadequate immunoregulatory mechanisms during pregnancy may lead to recurrent spontaneous abortion (RSA). $T_{H} 17$ cells play a significant role in inducing inflammation, autoimmune disease, and acute transplant rejection, while regulatory $\mathrm{T}$ (Treg) cells moderate the function of immune system in order to retain homeostasis.

\section{Methods}

This case-control study was designed to evaluate $T_{H} 17$ as well as Treg cells in 25 women with RSA and 25 age-matched healthy non-pregnant women. Flow cytometric assay was performed using monoclonal antibodies to detect $\mathrm{CD} 4^{+} \mathrm{CD} 25^{+}$Treg cells (CD25 dim and CD25 bright). FoxP3 and RORyt expressions were compared using real-time PCR, and pro-inflammatory and anti-inflammatory cytokines were measured by ELISA kits. Independent-samples T test was employed for statistical analysis.

\section{Results}

The ratio of $\mathrm{CD} 4^{+} \mathrm{CD} 25^{\text {bright }} \mathrm{T}$ cells was remarkably lower in women with $\mathrm{RSA}(P<0.05)$, and $\mathrm{CD} 4^{+} \mathrm{CD} 25^{\mathrm{dim}}$ T cells did not show any significant difference among the groups ( $P>0.05)$. RORyt was up-regulated, and FoxP3 was down-regulated significantly in case group $(P<0.05)$. The significant increase of IL-6 and IL-17 as well as the decrease of TGF- $\beta$ was indicated in RSA group $(P<0.05)$. Also, IL-10 did not vary among the groups $(P>0.05)$.

\section{Conclusion}

These remarks prove that the decrease in regulatory factors such as CD $4^{+} C D 25^{\text {bright }}$ T-cells, TGF- $\beta$ and FoxP3 expression may disrupt immune tolerance and homeostasis during pregnancy. Also, the environment rich in RORYt, IL-6, and IL-17 suggests the detrimental role of $T_{H} 17$ cells, which may lead to fetal rejection.

\section{Introduction}

Pregnancy is a complex and challenging event in which all organs of the mother such as immune system should adapt to new physiological changes emerging by the growing fetus to ensure a good and successful outcome. Since the fetus expresses paternal antigens, it is considered as a semi-allograft; however, due to the immune tolerance in the course of healthy pregnancy, maternal immune system tolerates the fetus and does not reject it. Any disruption in this immune tolerance and the appearance of improper immune responses against the fetus could affect the pregnancy outcome and may lead to disorders such as spontaneous abortion, which usually occurs in the first trimester of pregnancy [1]. While anatomic, genetic, endocrinologic, and coagulative disorders and infections have been implicated 
in etiology of RSA, immunological problems play a main role in this phenomenon[2]. The distribution and function of decidual immune cells have been frequently studied in normal and pathologic conditions. Uterine NK (UNK) cells, T-cells, and macrophages are principal subpopulations of leukocytes in decidua [3]. According to the traditional classification, $T$ lymphocytes are categorized into $T_{H} 1$ and $T_{H} 2$ subsets, which produce a variety of cytokines [4].

$\mathrm{T}_{\mathrm{H}} 17$ cells constitute an important subset of $\mathrm{CD} 4^{+}$T-cells secreting IL-17 and other pro-inflammatory cytokines, which play a significant role in host defense against extracellular bacterial and fungal agents, neutrophils recruitment, chronic inflammation, acute transplant rejection, and autoimmune disorders [5]. Retinoic acid-related orphan receptor yt (RORyt or RORC) has been reported to be a transcription factor involved in the development and expansion of $\mathrm{T}_{\mathrm{H}} 17$ cells [6].

Regulatory T (Treg) cells have been recognized as the main regulators of immune system, which modulate the impact of $T_{H} 17$ cells on inflammatory states [7]. Interestingly, $T_{H} 17$ and Treg cells stem from a single developmental lineage; therefore, there is a complicated relationship between them because progenitor cells differentiate into Treg cells in presence of TGF- $\beta$ alone, developing into $T_{H} 17$ cells under the influence of both TGF $\beta$ and IL-6 [8]. CD $4^{+}$CD $25^{+}$Treg cells have been identified as a subpopulation of T-cells having immunomodulatory and immunoregulatory function, which establish immune balance between the elements of immune system and enhance pregnancy outcome. Forkhead box P3 (FoxP3) has been recognized as a Treg-associated factor inducing generative, proliferative, and regulatory function of Treg cells [9]. Treg cells perform their immunomodulatory function by secreting IL-10 and TGF $\beta$ cytokines. Besides, TGF- $\beta$ stimulates the differentiation of Treg cells from $\mathrm{CD} 4^{+} \mathrm{CD} 25^{-} \mathrm{T}$ cells by FoxP3 augmentation[10] .

The delicate balance among the various components of immune system is crucial for maintenance of pregnancy. As well as predominant $T_{H}$ 1-type immunity, exaggerated $T_{H}$-type immunity has unfavorable effects, which may lead to RSA [11]. Since some of the immunological disorders could not be expounded by $T_{H} 1 / T_{H} 2$ paradigm, $T_{H} 17$ cells alter the $T_{H} 1 / T_{H} 2$ immune paradigm into $T_{H} 1 / T_{H} 2 / T_{H} 17 / T r e g$ framework. In this four-component model, all the elements interact in a complex network to retain immune tolerance during pregnancy. Due to the important role of $\mathrm{T}_{\mathrm{H}} 17$ and Treg cells in the maintenance of homeostasis, various researches have investigated the balance among these cells in healthy and pathogenic conditions. Some studies have reported the decrease of Treg cells and increase of IL-17producing cells in decidua and/or peripheral blood of women with RSA and preeclampsia disorders [12, 13].

Thus, to expand and confirm prior studies, we aimed to focus on $T_{H} 17$ and Treg cells and related agents in peripheral blood of women with RSA in comparison with healthy controls.

\section{Materials And Methods}

\section{Study population and sampling}


In our case-control study, a total of 50 women comprising 25 women with RSA and 25 healthy nonpregnant women were recruited. The RSA group was diagnosed by a gynecologist after exclusion criteria such as chromosomal abnormalities, anatomic disorders (uterine polyp, uterine septum, fibroid, pelvic adhesion), hormonal and metabolic diseases (thyroid disorders, polycystic ovarian syndrome, diabetes mellitus), immunological problems (autoimmune disease, existence of anti-phospholipid, anti-cardiolipin and anti-coagulant antibodies), coagulation dysfunction, and infection. All the selected women having RSA were in reproductive age with mean age of $29.1 \pm 0.8$ years and with the history of three or more repeated miscarriages with mean miscarriage of $3.2 \pm 0.1$. Also, the selected patients had a normal karyotype, their male partners were examined and had normal semen state.

For control group, 25 healthy non-pregnant women without a history of abortion or disorders during previous pregnancies were randomly selected. Healthy women were in reproductive age and had mean age of $29.9 \pm 0.7$ years and a minimum of one living child with the mean number of children of $1.8 \pm 0.1$. Also, their health status was assessed, and all of them had regular menstrual cycle, normal gynecological, hormonal, and anatomical conditions without any symptoms of infection.

It should be noted that at least three months had elapsed from the last miscarriage, pregnancy, or vaccination of participants, and all of them signed a written informed consent form before participation. The ethics review board of Ahvaz Jundishapur University of Medical Sciences (AJUMS) approved the current study

At secretory phase of menstrual cycle, venous blood was collected from all participants and transferred into three different tubes: one tube for flow cytometric analysis; an EDTA-contained tube for isolation of mononuclear cells using a lymphocyte separation medium for mRNA extraction and real-time PCR; and a clot activator containing tube for evaluation of serum cytokines.

\section{Flow cytometry}

$\mathrm{CD} 4^{+} \mathrm{CD} 25^{+}$Treg cells were determined using fresh blood and stained using FITC-conjugated anti-human CD4 and PE-conjugated anti-human CD25 antibodies (eBioscienc, California) according to manufacturer's instructions. Isotype control antibodies were used to ensure the specificity of antibodies as well as precise comparison. After eliminating RBCs by the lysis solution (DAKO cytomation, Germany) and washing with phosphate buffer saline (PBS), the samples were assessed using a FACS Calibur device (Becton Dickinson). CD $4^{+} \mathrm{CD} 25^{+}$(CD25 ${ }^{\text {dim }}$ and $C D 25^{\text {bright }}$ ) Treg cells were selected within the lymphocyte gate. Flowing Software v2.4.1 was used for flow cytometric analysis.

\section{RNA extraction, cDNA synthesis, and real-time PCR}

After isolating peripheral blood mononuclear cells (PBMCs) by lymphocyte separation medium (PAA, Germany), total RNA was extracted using Rneasy Mini Kits (QIAGEN, Valencia, CA) by observing the manufacturer's instructions. The quality of the extracted RNA was checked using Biophotometer (Eppendorf). cDNA synthesis was performed by QuantiTec Reverse Transcription kit (QIAGEN, Valencia, $\mathrm{CA}$ ) according to manufacturer's guidelines. Finally, the product was stored at $-80^{\circ} \mathrm{C}$ until use. The 
amplification was performed in an ABI Step One (Applied Biosystem, USA) PCR system using StepOne Software v2.1 and SYBR Green kit (Takara, Japan). All samples were run in duplicate with negative controls. The primer sequences were as follows: ROR C forward 5囚-AGACTCATCGCCAAAGCA-3\ and reverse 5囚-CCTTGTAGAGTGGAGGGAAA-3》 [14] as well as FoxP3 forward 5》-

CAGCACATTCCCAGAGTTCCT-3\ and reverse 5Х-GCGTGTGAACCAGTGGTAGAT-3囚[15]. Furthermore, the housekeeping gene GAPDH primers, namely forward 5囚-ACCACAGTCCATGCCATCAC-3》 and reverse 5》TCCACCACCCTGTTGCTGTA-3Х [16] were used as internal controls in all assays. The cycling conditions were as follows: $10 \mathrm{~min}$ at $95^{\circ} \mathrm{C}, 40$ cycles of $15 \mathrm{~s}$ at $95^{\circ} \mathrm{C}$ and $60 \mathrm{~s}$ at $60^{\circ} \mathrm{C}$. Finally, data were analyzed by REST 2008 v2.0.7 software based on threshold cycle (CT) values.

\section{Enzyme Linked Immunosorbent assay (ELISA)}

The concentrations of IL-6, IL-17, IL-10, and TGF- $\beta$ cytokines in serum were evaluated by ELISA according to manufacturer's instructions (Komabiotech, South Korea), and the samples were analyzed using a microtiter plate reader in $450 \mathrm{~nm}$ (TECAN, Austria).

\section{Statistical analysis}

Data analysis was done using SPSS statistical software (version 22; SPSS, Chicago, IL). According to Kolmogorov-Smirnov $Z$ test, the distribution of data was normal. Thus, independent-samples t-test was employed for comparison of case and control groups. Data were presented as mean \pm SEM (standard error of mean), and $P<0.05$ was considered statistically significant.

\section{Results}

\section{Age of participants}

The mean age of women with RSA and control group was $29.1 \pm 0.8$ years and $29.9 \pm 0.7$ years, respectively, and there was no significant difference in this regard $(P=0.441)$.

\section{Frequency of $\mathrm{CD} 4^{+} \mathrm{CD} 25^{+}$Treg cells in peripheral blood}

Whereas activated T-cells express CD25 marker, Treg cells present it in higher levels. Therefore, $\mathrm{CD} 4^{+} \mathrm{CD} 25^{+}$T-cells were subdivided into $\mathrm{CD} 4^{+} \mathrm{CD} 25^{\mathrm{dim}}$ and $\mathrm{CD} 4^{+} \mathrm{CD} 25^{\text {bright }}$ populations (Fig. 1 ), and Treg cells were detected within the $\mathrm{CD} 4^{+} \mathrm{CD} 25^{\text {bright }} \mathrm{T}$-cell subpopulation [17]. The frequency of $\mathrm{CD} 4^{+} \mathrm{CD} 25^{+} \mathrm{T}$ cell subpopulation was compared between the two groups, and the results are as follows. Women with RSA demonstrated lower levels of $C D 4^{+} C D 25^{\text {bright }} T$-cells as compared to healthy controls $(1.60 \pm 0.06 \%$ vs. $2.80 \pm 0.13 \% ; P<0.001)$. However, the frequency of $C D 4^{+} C D 25^{\text {dim }}$ T-cells $(10.98 \pm 0.89 \%$ vs. $12.90 \%$ $\pm 1.15 \%)$ and $C D 4^{+}$T-cells $(30.34 \pm 1.13 \%$ vs. $27.99 \pm 1.22 \%)$ did not vary significantly ( $P>0.05$ for both) among women with RSA and healthy group (Fig. 2).

\section{RORyt and FoxP3 expression}


GAPDH was assumed as the reference gene with reaction efficiency of 0.97. RORyt and FoxP3 were target genes with reaction efficiencies of 1.00 and 0.97 , respectively. RORYt mRNA was up-regulated 2.04fold in case group relative to healthy controls ( $P=0.026$; Fig. 3); FoxP3 mRNA was down-regulated in women with RSA by 0.53 -fold compared to healthy group ( $P=0.037$; Fig. 3 ).

\section{Serum IL-6, IL-10, IL-17, and TGF $\beta$ concentrations}

The concentrations of IL-6, IL-10, IL-17, and TGF- $\beta$ in serum were evaluated in healthy women as well as in women with RSA. A significant increase in the level of IL-6 $(336.10 \pm 23.62 \mathrm{pg} / \mathrm{ml}$ vs. $267.14 \pm 20.95$ $\mathrm{pg} / \mathrm{ml} ; P=0.034)$ and IL-17A $(200.81 \pm 23.82 \mathrm{pg} / \mathrm{ml}$ vs. $139.57 \pm 15.66 \mathrm{pg} / \mathrm{ml} ; P=0.037)$ cytokines was observed in RSA group. The concentration of TGF- $\beta$ was diminished significantly $(303.47 \pm 20.47 \mathrm{pg} / \mathrm{ml}$ vs. $374.74 \pm 21.12 \mathrm{pg} / \mathrm{ml} ; P=0.019)$ in women with RSA compared to healthy controls, but no significant difference was found in the level of IL-10 $(159.73 \pm 18.77 \mathrm{pg} / \mathrm{ml}$ vs. $168.90 \pm 14.29 \mathrm{pg} / \mathrm{ml} ; P>0.05)$ between the two groups (Fig. 4).

\section{Discussion}

It is interesting that during the process of pregnancy, the immune system of the mother accepts an allogeneic fetus and does not reject it, but why? More than 35 years ago, for the first time, the $T_{H} 1 / T_{H} 2$ hypothesis was propounded [18]. In this concept, type $1 \mathrm{CD}^{+} T$ helper cells $\left(T_{H} 1\right)$, which release proinflammatory cytokines such as IL-2 and IFN- $y$, have a role in cellular immunity, inflammation, and rejection process. On the contrary, type $2 \mathrm{CD} 4^{+} T$ helper cells $\left(T_{H} 2\right)$ are known as the mediators of humoral immunity, which secrete anti-inflammatory cytokines like IL-10, IL-5, IL-4, and so on and act in the opposite way to $T_{H}$ 1-type cytokines [19]. For many years, it was hypothesized that in the course of healthy pregnancy, a slight shift occurs from $T_{H}$ 1-type to $T_{H}$ 2-type immunity. However, later findings illustrated that the levels of both pro-inflammatory and inflammatory cytokines differ in various stages of pregnancy [20]. In animal autoimmune studies such as experimental autoimmune encephalomyelitis (EAE), many questions emerged that did not follow $T_{H} 1 / T_{H} 2$ solid dichotomy of immune balance [21]. A subpopulation of $C D 4^{+} T$ cells, namely $T_{H} 17$ cells, was a main point to solve the puzzle of autoimmune diseases. In addition to autoimmune diseases, $T_{H} 17$ cell studies have been extended in various fields such as host defense, metabolic dysfunctions, allergic disease, allograft rejection, and cancer immunology $[22,23]$.

We presumed that the overexpression of $T_{H} 17$ cells has a considerable role in pathogenesis of RSA. To determine this probability, we evaluated IL- 6 and IL-17 concentrations as well as RORyt expression in peripheral blood of women with RSA and control group. A significant increase was observed in the expression of RORyt and in the concentration of pro-inflammatory cytokines such as IL-6 and IL-17 among women with RSA. Although the frequency of $T_{H} 17$ cells was not determined by flow cytometric assay due to financial constraints, our results that demonstrate the enhancement of $T_{H}$ 17-related agents are in line with previous studies regarding $T_{H} 17$ cells. To obtain accurate results, recent studies have 
investigated $T_{H} 17$ cells in all aspects, including total number, receptor presentation, signaling pathway, cytokine production and gene expression in both peripheral blood and decidua. A number of studies in this field have reported the increase in proportion of $T_{H} 17$ cells, IL-17 and IL-23 cytokines as well as overexpression of RORyt as well as and the decrease of Treg in peripheral blood and/or decidua of women with RSA $[24,25]$. Activation of IL-17 might increase NF-KB expression, which reduces the quantity of progesterone receptors and weakens its function. Consequently, progesterone cannot bind a sufficient number of progesterone receptors, leading to decidua dysplasia and inadequate embryonic nutrition and finally resulting in miscarriage .[26] In another study, the association of IL-17 F gene polymorphism with a high risk of RSA among Iranian women has been reported [27]. A link has also been reported between polymorphisms in the genes of cytokines IL-1, TNF-a, and IL-17 with early pregnancy loss [28]. By producing pro-inflammatory cytokines, $T_{H} 17$ cells may enhance $T_{H} 1$ and NK cell activities, finally leading to abortion and preterm labor $[29,30]$. In this regard, the enhancement of NK cells number and activity has been demonstrated in women with RSA and those with IVF failure [31]. Besides, the increase of $\mathrm{TCD}^{+}$cells has been reported in women with repeated miscarriage [32]. Disturbance in immune regulation between $\mathrm{CD} 8^{+} \mathrm{T}$ cells and NK cells could increase NK cell activity, increasing the chance of reproductive failure and leading to RSA [33].

All of these findings imply that the increase of $T_{H} 17$ cells in women with RSA may augment the production of inflammatory cytokines and reinforce the function of effector cells such as NK cells and CD8 ${ }^{+}$T-cells. Thus, the synergistic effect of $T_{H} 17$ cells, NK cells, $C D 8^{+}$T-cells and pro-inflammatory products may expand exaggerated inflammatory environment and finally lead to fetal rejection and reproductive failure.

On the contrary, Treg cells that modulate the functions of effector T-cells such as $T_{H} 1, T_{H} 2$, and $T_{H} 17$ have a significant role in maintaining peripheral tolerance. Treg cells perform their regulatory function through the secretion of anti-inflammatory cytokines such as IL-10 and TGF- $\beta$. TGF- $\beta$ can elevate FoxP3 expression by inducing the expansion of $\mathrm{CD} 4^{+} \mathrm{CD} 25^{-} \mathrm{T}$-cells into Treg cells [9]. However, the presence of IL- 6 or activated dendritic cells may induce the differentiation of Treg cells into $T_{H} 17$ cells. Therefore, it can be concluded that inflammatory conditions predispose to switching of Treg cells into $T_{H} 17$ cells [34]. FoxP3 expression in humans is mainly restricted to $\mathrm{CD} 4^{+} \mathrm{CD} 25^{+} \mathrm{T}$ cells, but other subpopulations of $\mathrm{T}-$ cells such as $\mathrm{CD} 4^{+} \mathrm{CD} 25^{-}$and $\mathrm{CD} 8^{+} \mathrm{T}$ cells express it, too. Thus, it is supposed that FoxP3-expressing Tcells have suppressive and regulatory functions [35]. It is also known that Treg cells play a crucial role in restoring fetal maternal tolerance. The passive transfer of pregnancy-induced CD4+CD25+ Treg therapy has contributed to success of pregnancy and reduced the rate of spontaneous abortion among abortionprone mice [36]. Decrease of $\mathrm{CD}^{+} \mathrm{CD}_{2} 5^{+}$and FoxP3 ${ }^{+}$Treg cells has been reported in decidua and/or peripheral blood of women with RSA and missed abortion. The expression of full-length FOXP3 protein was reduced in women with RSA compared to control group [37]. Our findings were in line with previous studies because we demonstrated the reduction of $\mathrm{CD} 4^{+} \mathrm{CD} 25^{\text {bright }} \mathrm{T}$-cells, FoxP3 expression and TGF- $\beta$ 
concentration in peripheral blood of women with RSA. However, some studies have also reported that no significant difference is observed between the patient and control groups .[38]

Our study was performed at secretory phase of menstrual cycle. The enhancement of IL-6 and IL-17 secretion, the reduction of TGF- $\beta$, and no difference in IL-10 level were found at this phase among women with RSA. In contrast to our study, some researchers reported the increase of IL-17 at both proliferative and secretory phases and the decrease of TGF- $\beta$ and IL-10 only at proliferative phase among RSA group [24]. These controversies in studies may depend on variations in sample size and type (decidua or peripheral blood), time of sampling (secretory or proliferative phase, pregnancy or non-pregnancy conditions), and time elapsed from the last abortion.

Seminal fluid is a strong source of prostaglandin E and TGF- $\beta$, which induce the expansion of Treg cells after coitus for embryo implantation [39]. In the course of pregnancy, development of Treg cells in human and mice protects the invasive trophoblast cells containing fetal antigens against maternal immune system attack [40]. In animal models, the depletion of Treg cells could increase inflammation and lead to aberrant uterine artery function in mice [41]. Recent investigations in mouse models have indicated that adoptive transfer of Tregs can prevent pregnancy loss in these models by improving maternal tolerance. Hence, passive cell therapy by autologous Tregs could be a potential novel therapeutic approach for cellbased immunotherapy for women with repeated spontaneous abortion [42].

\section{Conclusion}

In conclusion, defects in immune regulatory mechanisms such as decreased number and function of regulatory T-cells and exaggerated $T_{H}$ 17-mediated inflammatory responses may threaten reproductive outcome, and this immunological imbalance might lead to disorders such as RSA during pregnancy. Moreover, adoptive Treg cell therapy could potentially be a therapeutic approach for these patients.

\section{Declarations}

\section{Acknowledgements}

We would like to express our gratitude to all the participants who contributed to this scientific work, especially the Deputy of Research affairs of Ahvaz Jundishapur University of Medical Sciences for financial support (grant No. FIRC-9103). The authors declare that there is no conflict of interest prejudicing the impartiality of this scientific research. This paper is issued from MSc thesis of Mina

\section{Badiee}

\section{Author contribution}

M.B, A.M.S. and R.N. carried out the experiment. M.B. wrote the manuscript with support from A.A.GH. and A.M.S. A.A.GH. and M.Gh. helped supervise the project. M.Gh. and R.N. conceived the original idea. M.Gh. supervised the project. R. Ch. analyzed the data. 


\section{Declaration of Interest}

The authors report no conflicts of interest.

\section{References}

1. Christiansen, O.B., Evidence-based investigations and treatments of recurrent pregnancy loss. Curr Opin Obstet Gynecol, 2006. 18(3): p. 304-12.

2. Liu, Y., et al., Etiology of spontaneous abortion before and after the demonstration of embryonic cardiac activity in women with recurrent spontaneous abortion. International Journal of Gynecology \& Obstetrics, 2015. 129(2): p. 128-132.

3. Liu, S., et al., The role of decidual immune cells on human pregnancy. Journal of reproductive immunology, 2017. 124: p. 44-53.

4. Geginat, J., et al., Plasticity of human CD4 T cell subsets. Frontiers in immunology, 2014. 5: p. 630.

5. Peck, A. and E.D. Mellins, Plasticity of T-cell phenotype and function: the Thelper type 17 example. Immunology, 2010. 129(2): p. 147-53.

6. McGeachy, M.J. and D.J. Cua, Th17 cell differentiation: the long and winding road. Immunity, 2008. 28(4): p. 445-53.

7. Akbar, A.N., et al., The dynamic co-evolution of memory and regulatory CD4+ T cells in the periphery. Nat Rev Immunol, 2007. 7(3): p. 231-7.

8. Yang, L., et al., IL-21 and TGF- $\beta$ are required for differentiation of human TH17 cells. nature, 2008. 454 p. 350-352

9. Plitas, G. and A.Y. Rudensky, Regulatory T cells: differentiation and function. Cancer immunology research, 2016. 4(9): p. 721-725.

10. Sakaguchi, S., et al., Regulatory T cells and human disease. Annual review of immunology, 2020. 38 : p. 541-566.

11. Comba, C., et al., Role of inflammatory mediators in patients with recurrent pregnancy loss. Fertility and sterility, 2015. 104(6): p. 1467-1474. e1.

12. Toldi, G., et al., Increased prevalence of IL-17-producing peripheral blood lymphocytes in preeclampsia. Am J Reprod Immunol, 2011. 66(3): p. 223-9.

13. Zhang, Z., et al., Regulatory effect of daphnetin on the balance of Th17 and Treg cells in the peripheral blood mononuclear cells from patients with unexplained recurrent pregnancy loss. CentralEuropean Journal of Immunology, 2020. 45(4): p. 403.

14. Wang, W.J., et al., Increased prevalence of T helper 17 (Th17) cells in peripheral blood and decidua in unexplained recurrent spontaneous abortion patients. J Reprod Immunol, 2010. 84(2): p. 164-70.

15. Brisslert, M., et al., Phenotypic and functional characterization of human CD25+ B cells. Immunology, 2006. 117(4): p. 548-57. 
16. Ichiyama, K., et al., Foxp3 inhibits RORgammat-mediated IL-17A mRNA transcription through direct interaction with RORgammat. J Biol Chem, 2008. 283(25): p. 17003-8.

17. Cao, D., et al., Isolation and functional characterization of regulatory CD25brightCD4+ $T$ cells from the target organ of patients with rheumatoid arthritis. Eur J Immunol, 2003. 33(1): p. 215-23.

18. Coffman, R.L. and J. Carty, A T cell activity that enhances polyclonal IgE production and its inhibition by interferon-gamma. J Immunol, 1986. 136(3): p. 949-54.

19. Walia, G., et al., Immuno-molecular etiology of recurrent pregnancy loss and the anthropological perspective. Int J Hum Genet, 2008. 8: p. s227-35.

20. Mor, G. and I. Cardenas, The immune system in pregnancy: a unique complexity. Am J Reprod Immunol, 2010. 63(6): p. 425-33.

21. Glatigny, S. and E. Bettelli, Experimental autoimmune encephalomyelitis (EAE) as animal models of multiple sclerosis (MS). Cold Spring Harbor perspectives in medicine, 2018. 8(11): p. a028977.

22. Ouyang, W., J.K. Kolls, and Y. Zheng, The biological functions of T helper 17 cell effector cytokines in inflammation. Immunity, 2008. 28(4): p. 454-67.

23. Liu, D., et al., Th17/IL-17 axis regulated by airway microbes get involved in the development of asthma. Current allergy and asthma reports, 2020. 20(4): p. 1-9.

24. Sereshki, N., et al., Variations in T-helper 17 and Regulatory T Cells during The Menstrual Cycle in Peripheral Blood of Women with Recurrent Spontaneous Abortion. Int J Fertil Steril, 2014. 8(1): p. 5966.

25. Guo, Z., et al., Analysis of chromosomes and the $T$ helper 17 and regulatory $T$ cell balance in patients with recurrent spontaneous abortion. Experimental and therapeutic medicine, 2020. 19(4): p. 31593166.

26. Sha, J., et al., Alteration of Th17 and Foxp3+ regulatory $T$ cells in patients with unexplained recurrent spontaneous abortion before and after the therapy of hCG combined with immunoglobulin. Experimental and therapeutic medicine, 2017. 14(2): p. 1114-1118.

27. Najafi, S., et al., Association of IL-17A and IL-17 F gene polymorphisms with recurrent pregnancy loss in Iranian women. J Assist Reprod Genet, 2014. 31(11): p. 1491-6.

28. Tatarkova, E., et al., Gene polymorphisms of IL-1B (C511T), IL-17A (G197A), IL-12B (A1188C), TNFa (G308A) and IL-4 (C589T) associated with threat of early reproductive losses. Medical Immunology (Russia), 2020. 21(6): p. 1179-1186.

29. Bansal, A.S., Joining the immunological dots in recurrent miscarriage. Am J Reprod Immunol, 2010. 64(5): p. 307-15.

30. Yu, Y., et al., Th1/Th17 cytokine profiles are associated with disease severity and exacerbation frequency in COPD patients. International Journal of Chronic Obstructive Pulmonary Disease, 2020. 15: p. 1287.

31. Karami, N., et al., Enhancement of peripheral blood CD56 dim cell and NK cell cytotoxicity in women with recurrent spontaneous abortion or in vitro fertilization failure. J Reprod Immunol, 2012. 95: p. 
87-92.

32. Ghafourian, M., A. Abuhamidy, and N. Karami, Increase of peripheral blood TCD8+ cells in women with recurrent miscarriage. Journal of Obstetrics and Gynaecology, 2014. 34(1): p. 36-39.

33. Yoo, J.H., et al., Peripheral blood NK cell cytotoxicities are negatively correlated with CD8(+) T cells in fertile women but not in women with a history of recurrent pregnancy loss. Am J Reprod Immunol, 2012. 68(1): p. 38-46.

34. Hosseini, A., et al., Regulatory $T$ and T helper 17 cells: Their roles in preeclampsia. Journal of cellular physiology, 2018. 233(9): p. 6561-6573.

35. Fontenot, J.D. and A.Y. Rudensky, A well adapted regulatory contrivance: regulatory $T$ cell development and the forkhead family transcription factor Foxp3. Nat Immunol, 2005. 6(4): p. 331-7.

36. Wang, W.-J., et al., Adoptive transfer of pregnancy-induced CD4+CD25+ regulatory $T$ cells reverses the increase in abortion rate caused by interleukin 17 in the CBA/J× BALB/c mouse model. Human reproduction, 2014. 29(5): p. 946-952.

37. Dirsipam, K., et al., Association of FOXP3 rs3761548 polymorphism and its reduced expression with Unexplained Recurrent Spontaneous Abortions: A South Indian Study. American Journal of Reproductive Immunology, 2021: p. e13431.

38. Quan, X. and X. Yang, Correlation between unexplained recurrent spontaneous abortion with CD4+ CD25+ regulatory T-cell and killer cell immunoglobulin-like receptor levels. Experimental and therapeutic medicine, 2017. 14(2): p. 1459-1462.

39. Robertson, S.A., et al., Seminal fluid and the generation of regulatory $T$ cells for embryo implantation. Am J Reprod Immunol, 2013. 69(4): p. 315-30.

40. Krop, J., et al., Regulatory T Cells in Pregnancy: It Is Not All About FoxP3. Frontiers in Immunology, 2020. 11(1182).

41. Care, A.S., et al., Reduction in regulatory T cells in early pregnancy causes uterine artery dysfunction in mice. Hypertension, 2018. 72(1): p. 177-187.

42. Mohammadi, S., et al., Adoptive transfer of Tregs: A novel strategy for cell-based immunotherapy in spontaneous abortion: Lessons from experimental models. International Immunopharmacology, 2021. 90: p. 107195.

\section{Figures}


(a)

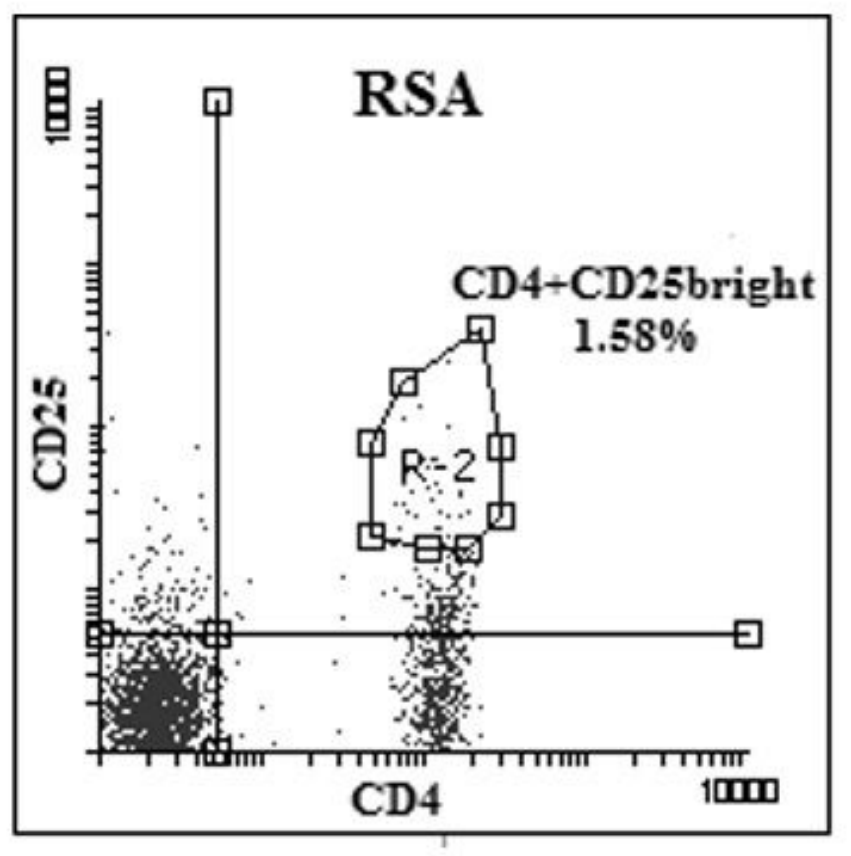

(b)

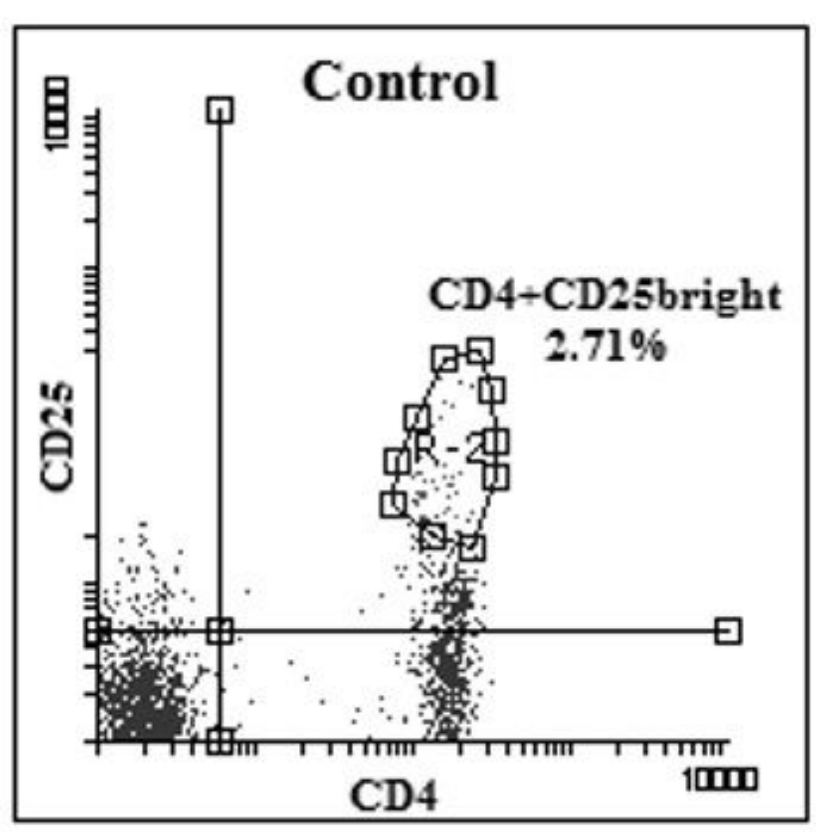

\section{Figure 1}

Indicative FACS staining of peripheral blood CD4+CD25+ T-cells from one of the women with RSA (a), and a healthy non-pregnant woman (b) are displayed. Peripheral blood mononuclear cells (PBMCs) stained for surface expression of CD4 and CD25 markers. Right Top quadrant shows CD4+CD25+ T-cells, and R-2 region represents $C D 4+C D 25$ bright $\mathrm{T}$-cells. 


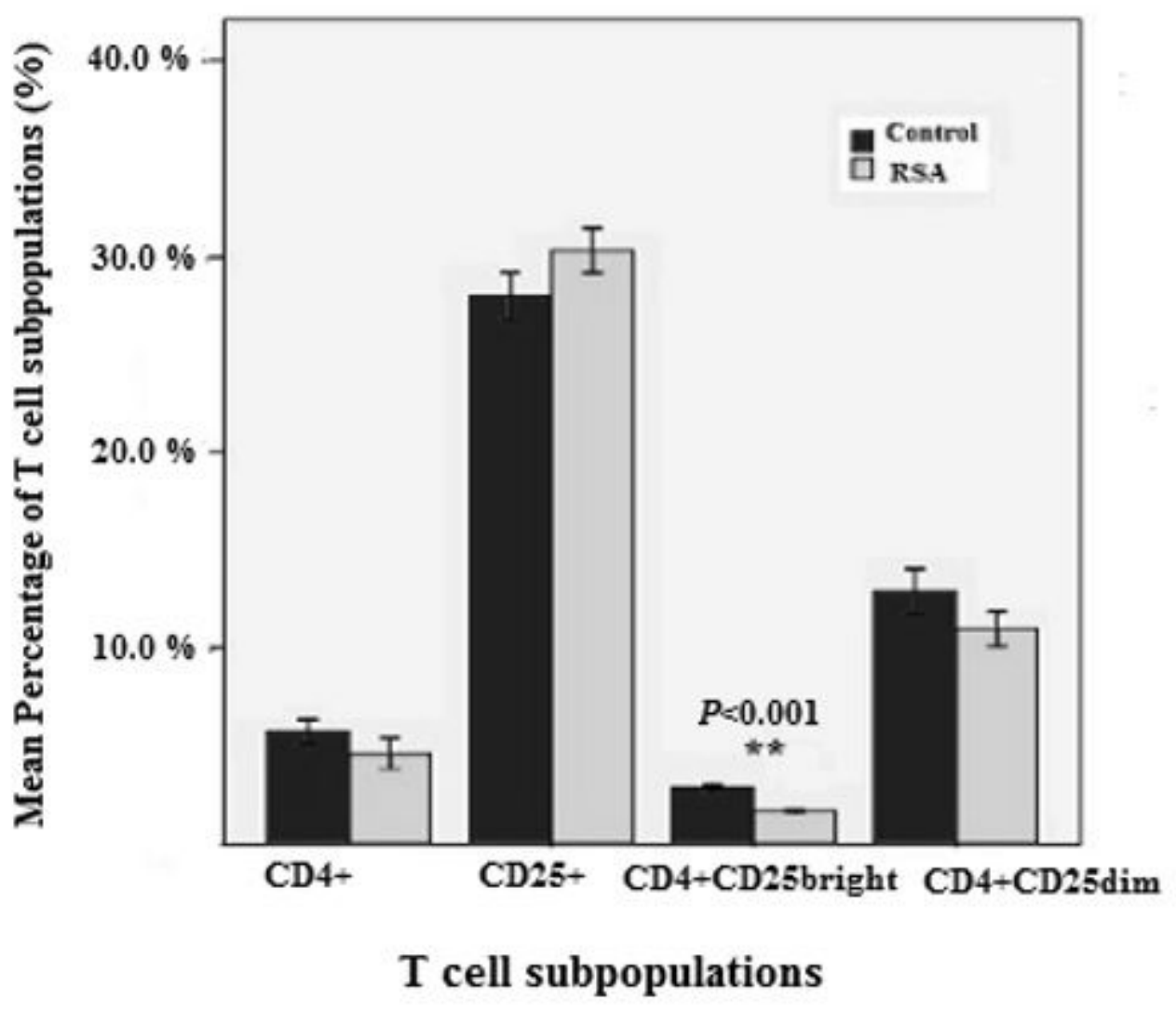

Figure 2

The percentages of CD25+, CD4+, CD4+CD25bright, and CD4+CD25dim T-cells in peripheral blood of women with RSA ( $n=25)$ and healthy non-pregnant group $(n=25)$. The significant difference of CD4+CD25bright T-cells is shown among the RSA and control groups $(* \star P<0.001)$. Bars demonstrate the mean. 


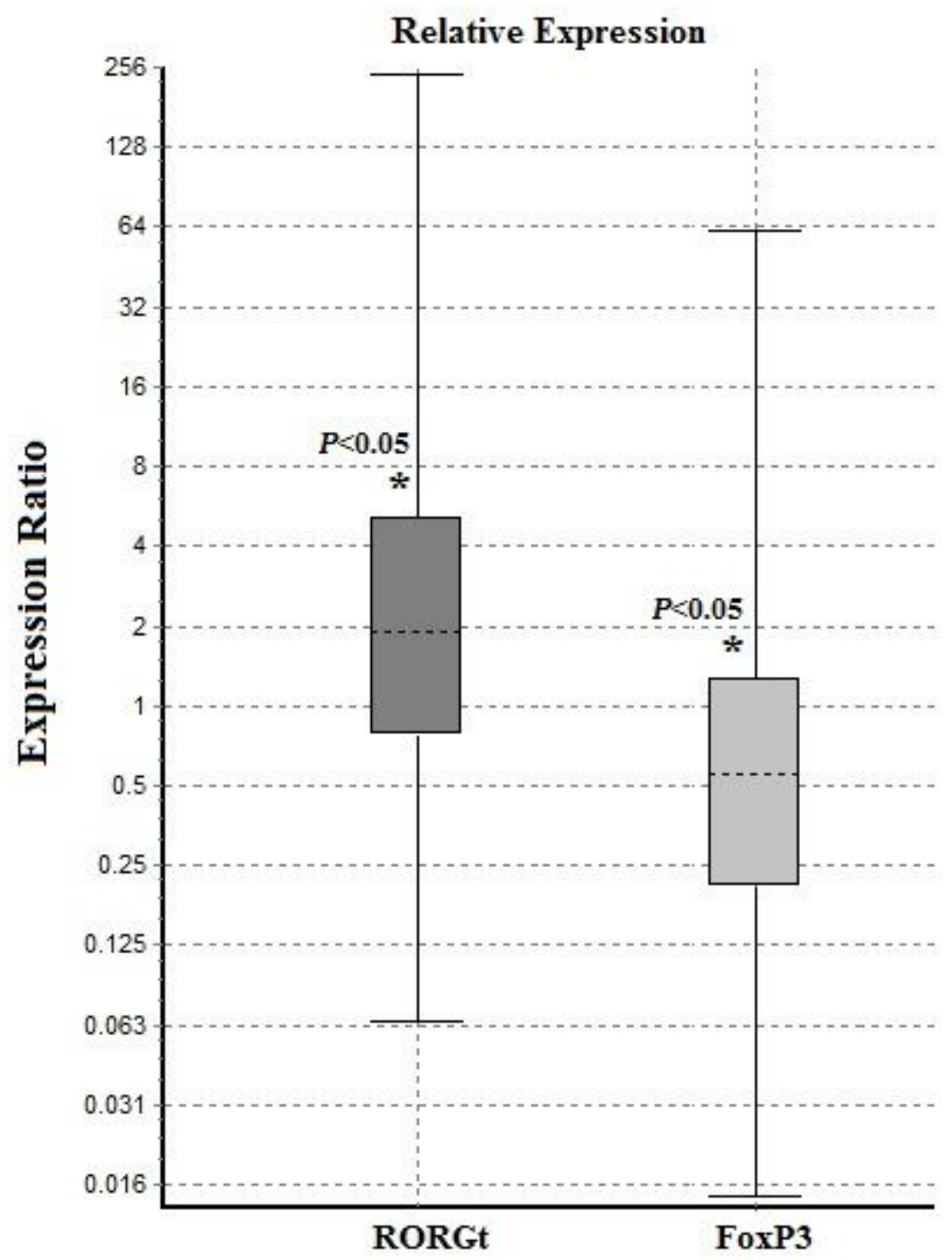

Figure 3

The relative expressions of RORyt and FoxP3 in peripheral blood mononuclear cells of RSA women $(n=25)$ as compared to healthy controls ( $n=25)$. RORyt is upregulated significantly in RSA group (in comparison to control group) by a mean factor of 2.04, and FoxP3 is downregulated significantly in RSA group (in comparison to control group) by a mean factor of $0.53\left({ }^{\star} \mathrm{P}<0.05\right)$. 


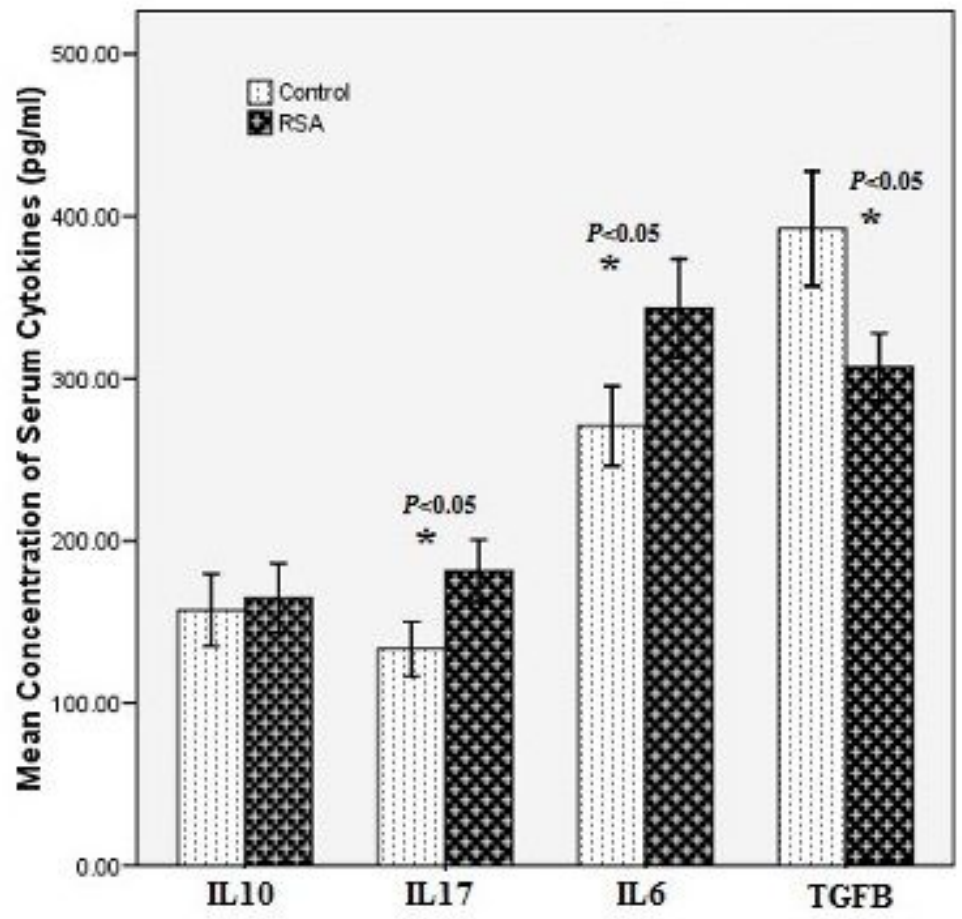

Figure 4

The comparison of serum cytokine levels, including IL-10, IL-17, IL-6, and TGF- $\beta$ among non-pregnant and RSA women. The concentrations of IL-6, IL-17, and TGF $\beta$ are significantly different in RSA group compared with healthy control women $\left({ }^{*} \mathrm{P}<0.05\right)$. Bars show the mean. 